\title{
BM] Global Health Multisite prospective investigation of psychological outcomes following cataract surgery in Vietnam
}

\author{
David Berle, ${ }^{1,2}$ Zachary Steel, ${ }^{2,3}$ Beverley M Essue, ${ }^{4}$ Lisa Keay, ${ }^{4}$ Stephen Jan, ${ }^{4}$ \\ Huynh Tan Phuc, ${ }^{5}$ Maree L Hackett, ${ }^{4}$ on behalf of the VISIONARY study team
}

To cite: Berle D, Steel Z, Essue BM, et al. Multisite prospective investigation of psychological outcomes following cataract surgery in Vietnam. BMJ Global Health 2017;2:e000162.

doi:10.1136/bmjgh-2016000162

Received 22 August 2016 Revised 25 November 2016 Accepted 11 December 2016

\section{(a) CrossMark}

${ }^{1}$ Graduate School of Health, University of Technology Sydney, Sydney, New South Wales, Australia

${ }^{2}$ School of Psychiatry, University of New South Wales (UNSW), Sydney, New South Wales, Australia ${ }^{3}$ St John of God Health Care, Richmond Hospital, North Richmond, New South Wales, Australia

${ }^{4}$ The George Institute for Global Health, The University of Sydney, Sydney,

New South Wales, Australia

${ }^{5}$ The Fred Hollows

Foundation Vietnam, Da Nang City, Vietnam

\section{Correspondence to}

David Berle;

david.berle@uts.edu.au

\section{ABSTRACT}

Background: Cataract surgery is a low-cost and effective intervention. There is increasing evidence to suggest that cataract surgery is associated with improvements in mobility, overall functioning and reductions in psychological distress. Within lowincome and middle-income countries, cataract surgery has also been documented to lead to reductions in psychological distress; however, differences in economic activity and engagement in paid and domestic work in these countries may moderate such reductions. We aimed to examine the psychological outcomes following cataract surgery among a diverse Vietnamese sample.

Methods: We report findings from the VISIONARY study, a 12-month multisite prospective study of cataract surgery outcomes conducted in Vietnam $(\mathrm{N}=462)$. Generalised estimating equations (GEEs) were used to identify the variables which were associated with reduced psychological distress.

Results: A high proportion of participants $(56.6 \%)$ reported psychological distress before surgery and severity of psychological distress had decreased by 12 months following surgery (95\% Cl (4.13 to 4.95)). There were regional differences in the extent of improvement in psychological distress and change in paid and unpaid work. The extent of improvement in visual acuity, male gender, and increase in paid and unpaid work hours were significant predictors of reductions in psychological distress.

Conclusions: Cataract surgery appears to result in the greatest reductions in psychological distress in communities where work engagement is highest.

Funding: The VISIONARY study was funded by a grant provided by the Fred Hollows Foundation, Australia. During the course of this work, BME was in receipt of an lan Potter Foundation Fellowship and a National Health and Medical Research Council (NHMRC) fellowship (1072148), SJ received an NHMRC Senior Research Fellowship, MLH was in receipt of a National Heart Foundation Future Leader Fellowship 100034.

\section{INTRODUCTION}

Cataracts are the leading cause of blindness in the world, accounting for $51 \%$ of blindness

\section{Key questions}

What is already known about this topic?

- There is accruing evidence that cataracts are also associated with multiple psychological comorbidities, including elevated rates of anxiety and depression.

- Cataract surgery is a low-cost and effective intervention for such visual impairment which may also lead to reductions in psychological distress in populations in low-income and middleincome countries (LMICs).

- A previous study of older people (aged $\geq 50$ years) in Vietnam found decreased depressive symptoms at $1-3$ months postsurgery.

- Improvements in depression and anxiety status 1 year following cataract surgery have also been documented among Kenyan, Filipino and Bangladeshi patients.

\section{What are the new findings?}

- This study is the first to investigate psychological and occupational outcomes from cataract surgery across multiple sites in Vietnam. We found that psychological outcomes 12 months following cataract surgery in Vietnam are associated with regional differences in the extent of household and paid work engagement.

\section{Recommendations for policy}

- Our findings have importance for the distribution and planning of cataract treatment services in LMICs. In communities where there are high levels of paid and unpaid employment, the psychological benefits of cataract surgery are likely to be significant. On the other hand, cataract services in localities with relatively lower levels of occupational engagement may require additional post-treatment follow-up services to ensure that the full range of benefits of cataract surgery are realised.

and $33 \%$ of visual impairment. ${ }^{1}$ In addition to visual impairment, cataracts are associated with difficulties in activities of daily living, social engagement, independent mobility and increased risk of falls. ${ }^{2}{ }^{3}$ There is 
accruing evidence that cataracts are also associated with multiple psychological comorbidities, including elevated rates of anxiety and depression. ${ }^{4-6}$ Cataract surgery is a low-cost and effective intervention for such visual impairment. ${ }^{7}$ Potential benefits of cataract surgery in alleviating the associated burden of psychological symptoms have been documented. ${ }^{8}$ Small-to-moderate reductions in depression and anxiety symptoms have been recorded in a randomised controlled trial of women aged 70 and over at the Queens Medical Centre in Nottingham, UK, ${ }^{9}$ as well as in observational studies from the UK and Australia. ${ }^{10}{ }^{11}$ Reduced rates of mental health service use in the year following surgery ${ }^{12}$ have also been recorded.

Within low-income and middle-income countries (LMICs), cataracts have a proportionately greater contribution to the prevalence of blindness ${ }^{13}$ and typically arise earlier in life, ${ }^{14}$ often in a context where there are less effective income and social protection safety nets. The earlier age of onset of cataracts and the limited access to surgery for large segments of the population in LMICs underscores the health burden that may accrue from mental health comorbidities and the potential role that surgery may play in mediating reductions in anxiety and depressive symptoms in LMIC settings. A study of urban-dwelling older people (aged $\geq 50$ years) in Vietnam, for example, found decreased depressive symptoms at 1-3 months postsurgery. ${ }^{15}$ Improvements in depression and anxiety status 1 year following cataract surgery have also been documented among Kenyan, Filipino and Bangladeshi patients. ${ }^{16}$

A range of factors may account for improvements in mental health following cataract surgery. Improved visual acuity may contribute to improved mood in its own right, or other factors associated with visual acuity, such as occupational functioning, may moderate improvements, particularly in settings where affected individuals are more likely to be within the peak of their occupational demands. A large body of evidence suggests that increased occupational engagement is associated with reductions in depressive symptoms, ${ }^{17}$ but this is yet to be investigated within an LMIC context where gainful activity may cover a broader spectrum from paid work to engagement in subsistence activities.

There are a number of key limitations of the existing research including high attrition rates, ${ }^{15}$ the exclusion of participants aged under 50 years ${ }^{16}$ despite cataracts affecting younger people in LMIC, and a restricted focus on tertiary inpatient surgery rather than community outreach intervention programmes. There are also limited data on the interaction between paid employment and regional variation in employment. In countries like Vietnam, there are often unique forms of production and economic activity which define particular localities. For instance, with continued development, economic production has tended to become geographically concentrated ${ }^{18}$ with residential developments established around specific industries accentuating regional differences in population structure.
Finally, there is evidence to suggest that south-east Asian communities are more likely to employ a somatopsychic mode of symptom presentation ${ }^{19}{ }^{20}$ where people in psychological distress report symptoms using physical terms. Negative affect, in contrast, refers to negative mood states ${ }^{21}$ and loss of pleasure in activities ${ }^{22}$ and may be less frequently reported in east Asian communities when compared with western populations. It is important that research incorporate measures that address such cultural idiomatic expressions of distress.

In the VISIONARY study, we aimed to determine whether cataract surgery in Vietnam was associated with reductions in psychological distress at 12 months postsurgery, consistent with previous investigations in LMIC. ${ }^{15}{ }^{16}$ We used the Self-Reporting Questionnaire-20 (SRQ-20) to assess psychological distress, given that it incorporates somatic symptoms and has been previously validated in the Vietnamese population. Our secondary aims were to determine the socioeconomic predictors of changes in such distress following surgery. In particular, we sought to investigate if increased engagement in work following surgery would be associated with reductions in psychological distress. Finally, we sought to determine whether improvements in psychological distress were confined to somatic symptoms, in line with cultural expressions of psychological distress.

\section{METHODS}

The design of the study has been reported in full previously. ${ }^{23}$ A prospective cohort study of 462 adults aged 18 and over was conducted in four provinces of Vietnam: Thua Thien-Hue, Binh Dinh, Vinh Long and Thai Binh.

\section{Participants}

People with cataracts were recruited from outreach screening programmes and from the health facility in each region. They were invited to participate if the clinical assessment of their best uncorrected vision was $\leq 6 / 18$ in the better eye and if they had no prior cataract surgery. Cataract surgery involved phacoemulsification or extracapsular extraction, also referred to as small incision cataract surgery. The cost of surgery was decided by each facility and the cost of treatment (if any) was dependent on the health insurance status of the patient. Consenting participants were interviewed face to face before surgery (following vision assessment; 'baseline') and at 6 and 12 months postreferral by trained interviewers using structured paper-based questionnaires. Baseline assessments were conducted between April and November 2011. The average follow-up assessment was conducted 357 days $(\mathrm{SD}=59)$ after the baseline assessment during November 2012.

Participants were recruited from four sites: (1) Hue Eye Hospital in Thua Thien-Hue in Central Vietnam (population 1.1 million; main industries tourism, agriculture, forestry and fishing) $;^{24}$ (2) Thai Binh Eye Hospital in Thai Binh, on the Red River Delta 
(population 1.8 million; main industries agriculture and textiles) ${ }^{25}$ (3) Binh Dinh Eye Hospital in Binh Dinh in the Central of Vietnam (population 1.5 million; main industries agriculture and furniture manufacture) $;{ }^{24}$ (4) Vinh Long Social Disease Centre in Vinh Long in the Mekong Delta (population 1.0 million; main industry is agriculture).$^{26}$

\section{Measures}

Sociodemographic, medical, health service use, quality of life, household economic, psychological symptoms and vision-related surgical outcomes (uncorrected visual acuity and complications from cataract surgery) were assessed at each interview. Psychological symptoms were assessed using the Vietnam Version of the SRQ-20. ${ }^{27}$ The SRQ-20 assesses the presence (or absence) of 20 depressive, anxiety and somatic symptoms (hereafter referred to jointly as symptoms of psychological distress) during the past month. ${ }^{28}$ It has been found to be a reliable and valid instrument for screening for mental disorders in developing countries ${ }^{29-32}$ and the Vietnamese translation has been validated among community samples in Vietnam. ${ }^{27} 33$ In validating the SRQ-20 in a large $(\mathrm{N}=4980)$ Vietnamese sample, three factors were identified: negative affect (nine items; incorporating loss of pleasure in activities, feeling unhappy, difficulty making decisions), somatic symptoms (eight items; including fatigue, poor sleep, poor appetite) and hopelessness (three items; including feeling worthless and thoughts of suicide). Total scores range from 0 to 20 with lower scores indicating fewer symptoms of psychological distress.

Occupational engagement was assessed using items from the Vietnamese Household Living Standards Survey. ${ }^{35}$ Participants were asked the average number of hours per week that they had worked during the preceding month. At 12 months, participants were asked whether, and in what capacity, they had returned to work (paid and unpaid) and whether they were working in the same, or a similar job to the previous one. The perceived impact of visual acuity on the ability to return to work was also assessed.

In this paper, we report on results from the SRQ-20 and occupational data collected at baseline and 12-month follow-up.

Human Research Ethics Committee approval was obtained from the University of Sydney (13407) and all participants provided written informed consent using certified translations of approved participant information and consent forms.

\section{Data analysis}

All analyses were conducted in SPSS V.22 (IBM Corporation. IBM SPSS Statistics for Windows, Version 22.0. Armonk, NY: IBM Corp, 2013). The $\chi^{2}$ and one-way analysis of variance (ANOVA) models were used to investigate between-site differences in demographic characteristics and key variables (psychological distress, visual acuity, and paid and unpaid work hours). For significant ANOVA results, additional pairwise t-tests were conducted to compare individual sites on the respective variables. Bonferroni corrections were used to control the type 1 error rate.

To determine which variables predicted change in symptoms of psychological distress in the 12 months following referral for surgery, a generalised estimating equations (GEEs) approach was used. In contrast to repeated measures ANOVA, GEE models provide an approach to the analysis of longitudinal data that involves examination of the average population changes by included covariates without including assumptions regarding the underlying covariance structure. ${ }^{36}$ We constructed a hierarchical GEE model in three steps: first, the key hypothesis-related variables of change in visual acuity and paid work hours were entered as well as the methodologically important variables of site and place of recruitment (hospital vs outreach). Demographic variables were added at the second step (gender, education, marital status, age and unpaid work hours) and an interaction term (change in visual acuity $\times$ change in paid work) was entered at the third level. The interaction term was included to determine whether the benefits of improved visual acuity on SRQ-20 scores were even greater for those engaged in paid work.

On the basis that meaningful subscales of the SRQ-20 have been identified in the Vietnamese population, ${ }^{22}$ we repeated the above analyses for the negative affect and somatic symptoms subscales. ${ }^{22}$ We did not analyse the results for the hopelessness subscale as it had a low internal consistency (Cronbach $\alpha=0.20$ at baseline) and most participants $(89.1 \%)$ did not endorse the three constituent items.

\section{RESULTS}

Four hundred and eighty participants completed baseline interviews and 381 completed the 12-month follow-up $(82.5 \%)$. A further 14 participants attended the 12-month follow-up but did not complete the SRQ-20. Participants who did not attend the 12-month follow-up were older $(\mathrm{t}=4.10, \mathrm{df}=1, \mathrm{p}<0.001)$ and less likely to be married $\left(\chi^{2}=5.6, \mathrm{df}=1, \mathrm{p}=0.02\right)$. There were no other significant differences between completers and non-completers in demographic characteristics at baseline (figure 1).

At the baseline assessment, $56.6 \%$ of participants (207 of 366 participants with available data) scored equal to or above the accepted threshold of 8 on the SRQ-20 for probable psychological distress. This contrasts with $19.2 \%$ of community-based samples in Vietnam. ${ }^{33}$

The demographic characteristics of the sample are summarised by site in table 1 . Among the 381 participants attending the follow-up assessment, there were significant differences in key variables across recruitment sites in marital status (a greater proportion of married participants at site 3 compared with all other sites), age 


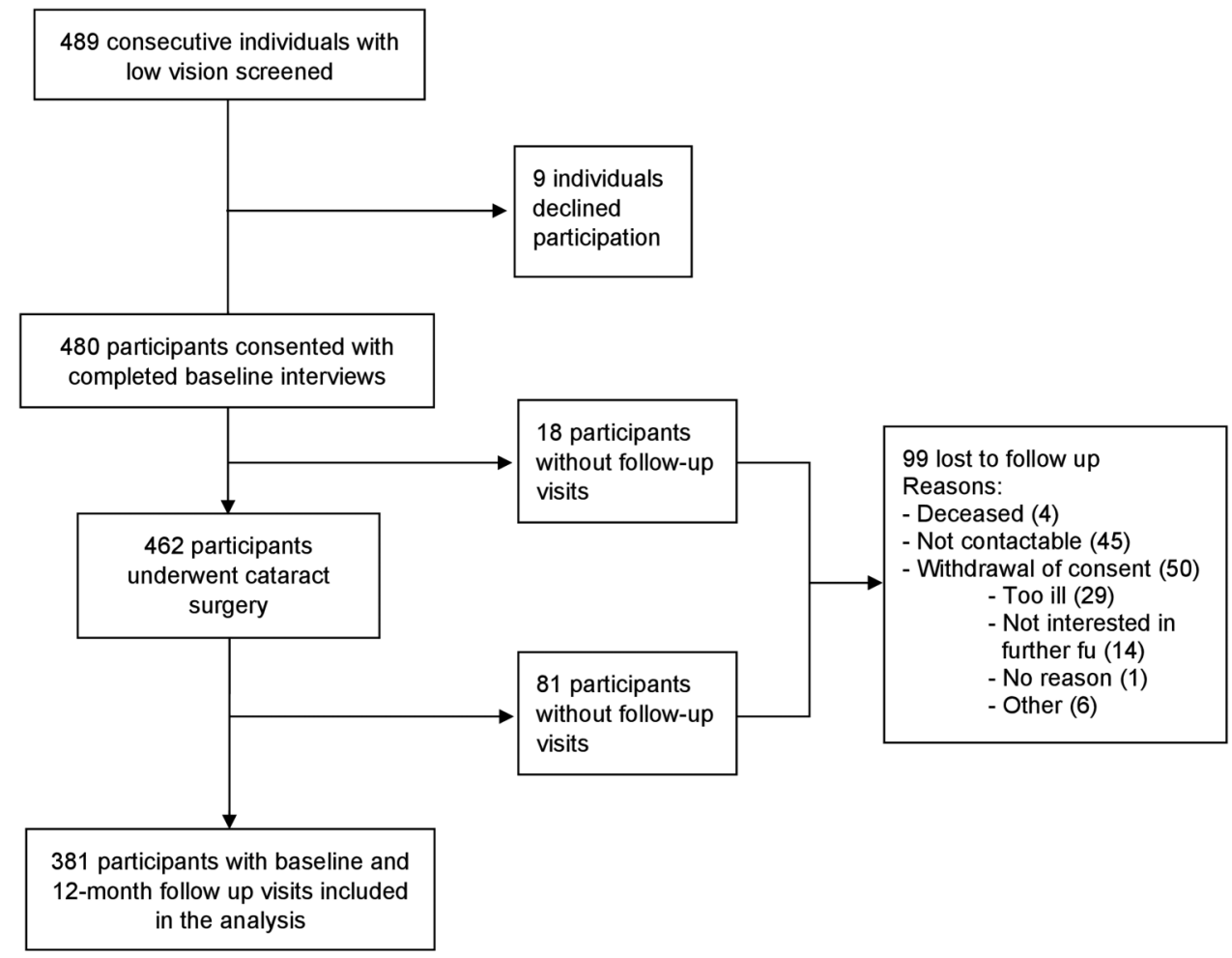

Figure 1 Flow of participants through the study. Reprinted from Ophthalmology, 121, Essue et al, A multicentre prospective cohort study of quality of life and economic outcomes after cataract surgery in Vietnam: The VISIONARY study, 2138-2146, (2011), with permission from Elsevier. fu, follow-up.

Table 1 Demographic characteristics and summary scores for key variables at baseline (each site and total sample) of VISIONARY participants for whom there were 12-month data available

\begin{tabular}{|c|c|c|c|c|c|c|}
\hline & Site $1(n=92)$ & Site $2(n=97)$ & Site $3(n=98)$ & Site 4 ( $n=94)$ & $\begin{array}{l}\text { Total sample } \\
(\mathrm{N}=381)\end{array}$ & $\begin{array}{l}\text { Between-site } \\
\text { comparisons } \$\end{array}$ \\
\hline & n (\%) & n (\%) & n (\%) & n (\%) & $\mathrm{N}(\%)$ & \\
\hline Female & $59(64.1)$ & $67(69.1)$ & 69 (72.6) & $49(52.1)$ & $244(64.0)$ & $2,3>4$ \\
\hline Agef, mean (SD) & 73.9 (12.7) & $68.0(11.0)$ & $71.7(8.1)$ & 67.5 (11.3) & $70.2(11.1)$ & $1>2,4 ;$ and $3<4$ \\
\hline
\end{tabular}

${ }^{*} \mathrm{~N}=368$ available data points.

$+\mathrm{N}=346$ available data points.

$\ddagger \mathrm{N}=379$ available data points.

$\S$ For $\chi^{2}$ tests, pairwise comparisons were performed, and for age, Bonferroni post hoc tests following a significant one-way ANOVA (agexsite) were conducted.

ANOVA, analysis of variance; NS, no significance.

(site 2 participants were younger than those at sites 1 and 3) and the proportion of participants recruited from hospital compared with an outreach screening programme $(93.2 \%$ recruited from a hospital setting in site 1 , greater than sites $3(58.5 \%)$ and $4(48.3 \%)$, which were in turn greater than site $2(0 \%))$.

In table 2, we present the means and SDs of visual acuity, paid and unpaid work hours and each of the respective SRQ-20 scores grouped by site. Prior to surgery, the mean total score for those affected by cataract was 7.9 , which was above the population cut-off of 7.0 for clinically meaningful psychological distress (64.3\% of sample) identified in the Vietnam population sample used to validate the SRQ-20. ${ }^{27}$ Following surgery, visual acuity improved and SRQ-20 scores reduced to a mean of 3.3, substantially below the recommended clinical cut-off for psychological distress $(91.6 \%$ of sample scoring below 8).

There were individual site differences for most variables at baseline. Compared with other sites, site 4 
Table 2 Key VISIONARY participant characteristics by site and time point

\begin{tabular}{|c|c|c|c|c|c|c|c|c|c|c|c|c|}
\hline & \multicolumn{2}{|l|}{ Site 1} & \multicolumn{2}{|l|}{ Site 2} & \multicolumn{2}{|l|}{ Site 3} & \multicolumn{2}{|l|}{ Site 4} & \multicolumn{2}{|c|}{ Total sample } & \multirow[b]{2}{*}{ Baseline $^{*}$} & \multirow[b]{2}{*}{ Follow-up† } \\
\hline & $\begin{array}{l}\text { Baseline } \\
\text { mean } \\
(\mathrm{SD})\end{array}$ & $\begin{array}{l}\text { Follow-up } \\
\text { mean (SD) }\end{array}$ & $\begin{array}{l}\text { Baseline } \\
\text { mean } \\
\text { (SD) }\end{array}$ & $\begin{array}{l}\text { Follow-up } \\
\text { mean (SD) }\end{array}$ & $\begin{array}{l}\text { Baseline } \\
\text { mean } \\
\text { (SD) }\end{array}$ & $\begin{array}{l}\text { Follow-up } \\
\text { mean (SD) }\end{array}$ & $\begin{array}{l}\text { Baseline } \\
\text { mean (SD) }\end{array}$ & $\begin{array}{l}\text { Follow-up } \\
\text { mean (SD) }\end{array}$ & $\begin{array}{l}\text { Baseline } \\
\text { mean (SD) }\end{array}$ & $\begin{array}{l}\text { Follow-up } \\
\text { mean (SD) }\end{array}$ & & \\
\hline Visual acuity & $1.44(0.79)$ & $0.49(0.36)$ & $1.45(0.72)$ & $0.49(0.28)$ & $1.14(0.68)$ & $0.69(0.44)$ & $1.19(0.82)$ & $0.50(0.40)$ & $1.30 \ddagger(0.77)$ & $0.54(0.38)$ & $1,2>3$ & $\begin{array}{l}1,2<3 \\
3<4\end{array}$ \\
\hline $\begin{array}{l}\text { Paid work } \\
\text { hours per day }\end{array}$ & 1.98 (3.19) & 2.34 (3.18) & 2.39 (3.25) & $1.25(2.42)$ & $2.73(2.95)$ & $3.76(2.66)$ & $5.34(4.99)$ & $6.49(4.28)$ & $3.14(3.90)$ & $3.44(3.74)$ & $1,2,3<4$ & $1,2<3<4$ \\
\hline $\begin{array}{l}\text { Unpaid work } \\
\text { hours per day }\end{array}$ & $2.37(2.21)$ & 3.21 (2.37) & $2.49(2.15)$ & 1.73 (2.33) & $1.80(1.79)$ & $5.04(3.14)$ & $3.02(1.70)$ & $8.92(4.01)$ & $2.41 \ddagger(2.00)$ & $4.68(4.06)$ & $3<4$ & $2<1<3<4$ \\
\hline $\begin{array}{l}\text { SRQ-20 } \\
\text { negative affect } \\
\text { score }\end{array}$ & $2.03(2.46)$ & $0.14(0.65)$ & 2.52 (1.63) & $1.49(1.33)$ & $3.90(1.55)$ & $0.71(1.15)$ & $4.17(1.95)$ & $0.34(0.86)$ & $3.15 \ddagger(2.10)$ & $0.67(1.13)$ & $1,2<3,4$ & $\begin{array}{l}1<3<2 \\
4<2\end{array}$ \\
\hline $\begin{array}{l}\text { SRQ-20 } \\
\text { somatic } \\
\text { symptoms } \\
\text { score }\end{array}$ & 3.27 (3.06) & $0.56(1.32)$ & $3.67(1.84)$ & $3.00(1.43)$ & 4.03 (1.97) & $2.24(1.58)$ & $7.12(1.04)$ & $4.55(2.75)$ & $4.53 \ddagger(2.57)$ & $2.60(2.34)$ & $1,2<3,4$ & $1<3<2<4$ \\
\hline $\begin{array}{l}\text { SRQ-20 } \\
\text { hopelessness } \\
\text { score§ }\end{array}$ & $0.04(0.25)$ & $0.00(0.00)$ & $0.29(0.52)$ & $0.23(0.45)$ & $0.05(0.22)$ & $0.03(0.17)$ & $0.14(0.38)$ & $0.00(0.00)$ & $0.13 \ddagger(0.37)$ & $0.06(0.26)$ & $\begin{array}{l}1<2 \\
2<3,4\end{array}$ & $1,3,4<2$ \\
\hline $\begin{array}{l}\text { SRQ-20 total } \\
\text { score }\end{array}$ & $5.23(5.29)$ & $0.70(1.78)$ & $6.60(2.87)$ & $4.70(2.06)$ & $8.01(3.12)$ & $2.97(2.14)$ & $11.43(2.73)$ & 4.89 (3.22) & $7.86 \ddagger(4.29)$ & $3.32(2.90)$ & $\begin{array}{l}1<3<4 \\
2<4\end{array}$ & $\begin{array}{l}1<3<2 \\
1,3<4 \\
\end{array}$ \\
\hline \multicolumn{13}{|c|}{$\begin{array}{l}\text { `Post hoc Bonferroni pairwise comparisons }(p<0.05) \text { at baseline. } \\
\text { †Post hoc Bonferroni pairwise comparisons }(p<0.05) \text { at follow-up. } \\
\text { †Significant differences between baseline and } 12 \text {-month follow-up (repeated measures t-test } p<0.05) \text {. } \\
\text { §Owing to a significant 'floor' effect, in that few participants in the overall sample endorsed the hopelessness-related items, between-group analyses were not conducted for this variable. } \\
\text { SRQ-20, Self-Reporting Questionnaire-20. }\end{array}$} \\
\hline
\end{tabular}

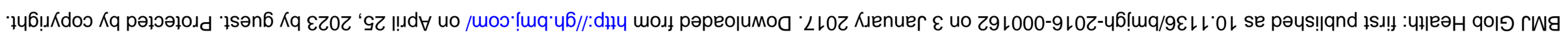


participants had the greatest psychological distress, worked the most hours per day in paid employment and reported the highest SRQ-20 negative affect (site 3 notwithstanding) and somatic symptoms subscale scores. In addition, participants at site 4 showed a greater increase in paid work and unpaid work hours between the baseline assessment and 12-month follow-up when compared with the average across other sites (mean increase in paid work $=1.09$ hours per day for site 4 vs 0.05 for the average across sites 1,2 and $3 ; \mathrm{t}=2.36, \mathrm{df}=131.70, \mathrm{p}=0.02$; mean increase in unpaid work hours per day for site $4=6.24$ vs 1.33 for the average across sites 1,2 and 3 ; $\mathrm{t}=9.94, \mathrm{df}=142.42, \mathrm{p}<0.001)$.

Three hundred and thirty-nine participants provided sufficient data at baseline and 12 months to allow the GEE models to be estimated (see table 3). In the first step of the analysis, participants from site 4 and hospital participants showed greater reductions in SRQ-20 total scores compared with participants at other sites and outreach participants, respectively $(\mathrm{p}<0.001)$. Likewise, a greater degree of improvement in visual acuity and increased hours of paid employment were significant predictors of decreased SRQ-20 total scores. At the second level, male gender and greater increases in unpaid work were significantly associated with greater reductions in SRQ-20 total scores. At the third level, the interaction of change in visual acuity and change in paid work hours was not significantly associated with change in the SRQ-20 total score.

The GEE analyses were also estimated for SRQ-20 subscales and the pattern of results was the same as those for the SRQ-20 total score, with the exception that (1) reductions in SRQ-20 negative affect scores were also significantly predicted by postschool education, and (2) reductions in SRQ-20 somatic symptom scores were also predicted by younger age.

\section{DISCUSSION}

These results provide further evidence that, in addition to visual impairment, cataracts are associated with substantially heightened levels of psychological distress in affected populations within LMIC settings, an observation that is consistent with those from high-income countries. ${ }^{15} 16$ We also found that improvements in visual acuity following surgery were an independent predictor of reduced psychological distress. Our multisite design highlighted differential reductions in psychological distress across settings (hospital vs outreach and site). The between-site differences may have been contributed to by complex interactions between the demographic characteristics of each site (eg, gender, age, marital status) and our key outcome variables.

Increases in paid and unpaid work following surgery were associated with reductions in psychological distress. This suggests that increased engagement in paid and domestic work may lead to an improved sense of selfefficacy and satisfaction and, in turn, improved psychological well-being. To the best of our knowledge, this question has not been investigated specifically in relation to unpaid work. Our findings reinforce the importance of ensuring that a person who is unemployed is not denied access to cataract surgery. ${ }^{37} 38$ The policy implications of these findings might be further highlighted if future studies are able to quantify the economic benefits associated with such postsurgical increases in unpaid work. We previously reported from this sample an increase in annual income associated with paid work following cataract surgery (US\$271pa; $17 \%$ of sample experiencing reduction in economic hardship $)^{39}$ indicating that the economic benefits associated with increased unpaid work may also be substantial. Future work may also examine whether other work-related characteristics, such as the transition from part-time to full-time employment, are also associated with favourable psychological outcomes.

The GEE model supported the role of improvements in visual acuity and work hours on reductions in psychological distress. Further research might aim to determine the temporal sequencing of increased engagement in paid work and reductions in psychological distress and thereby indicate a potential avenue by which the benefits of cataract surgery might be maximised (eg, through economic interventions to increase paid work engagement and, in turn, psychological well-being or, alternatively, psychological interventions to reduce psychological distress and, in turn, engagement in paid work).

We also found that reductions in psychological distress were reflected in improvements in somatic symptoms and negative affect by the 12-month follow-up. In this respect, the psychological benefits arising from cataract surgery are likely to be evident beyond the culturally consistent focus on somatic symptoms in this population $^{20}$ and extent to self-reported mood (eg, Do you feel unhappy?) and cognitive symptoms (eg, Do you have difficulty making decisions?).

The present findings need to be considered in the light of the limitations of the study. We measured uncorrected visual acuity, which is standard practice in Vietnam. Hence, the visual acuity of individuals with corrected vision, such as through the use of glasses, may be discrepant from their uncorrected visual acuity. We also relied on self-reported psychological distress at interview and were unable to confirm psychiatric diagnoses. For this reason, conclusions from the present study should be confined to the construct of psychological distress, rather than extend to specific psychological diagnoses. ${ }^{40}$ Finally, although this study was multisite, the findings may not necessarily generalise to the general population of Vietnam, especially given the regional differences. Nonetheless, the divergent findings across the sites in this study provide important insights into the degree of regional variability in the relationship between cataract surgery and improvements in work engagement and reductions in psychological distress. 
Table 3 Generalised estimating equations predicting SRQ-20 scores

\begin{tabular}{|c|c|c|c|c|c|c|c|c|c|}
\hline & \multicolumn{3}{|c|}{ SRQ-20 negative affect score } & \multicolumn{3}{|c|}{ SRQ-20 somatic symptom scores } & \multicolumn{3}{|c|}{ Total SRQ-20 score } \\
\hline & $\overline{\boldsymbol{\beta}}$ & SE & $\begin{array}{l}\text { 95\% Wald CI } \\
\text { Lower, upper }\end{array}$ & $\overline{\boldsymbol{\beta}}$ & SE & $\begin{array}{l}\text { 95\% Wald CI } \\
\text { Lower, upper }\end{array}$ & $\overline{\boldsymbol{\beta}}$ & SE & $\begin{array}{l}\text { 95\% Wald Cl } \\
\text { Lower, upper }\end{array}$ \\
\hline \multicolumn{10}{|l|}{ Step 1: main variables } \\
\hline (Intercept)† & 0.78 & 0.14 & 0.51 to $1.05^{\star}$ & 1.68 & 0.17 & 1.36 to $2.01^{*}$ & 2.34 & 0.28 & 1.79 to $2.89^{*}$ \\
\hline Site 1, 2, 3 vs 4 (index) & 0.71 & 0.16 & 0.40 to $1.01^{*}$ & 3.51 & 0.17 & 3.17 to $3.86^{*}$ & 4.27 & 0.30 & 3.68 to $4.87^{*}$ \\
\hline Outreach vs hospital (index) & 0.33 & 0.13 & 0.07 to $0.58^{*}$ & 0.81 & 0.16 & 0.49 to $1.14^{*}$ & 1.22 & 0.27 & 0.68 to $1.76^{*}$ \\
\hline Change in visual acuity $\ddagger$ & 0.98 & 0.11 & 0.76 to $1.20^{*}$ & 0.94 & 0.11 & 0.71 to $1.16^{*}$ & 2.12 & 2.10 & 1.71 to $2.53^{*}$ \\
\hline Change in paid work hours per day & -0.002 & 0.001 & -0.003 to $-0.00005^{\star}$ & -0.004 & 0.0009 & -0.006 to $-0.002^{*}$ & -0.006 & 0.002 & -0.009 to $-0.003^{\star}$ \\
\hline \multicolumn{10}{|l|}{ Step 2: including demographics } \\
\hline Female vs male (index) & 0.40 & 0.16 & 0.10 to $0.71^{*}$ & 1.14 & 0.19 & 0.78 to $1.51^{*}$ & 1.64 & 0.33 & 0.10 to $2.27^{\star}$ \\
\hline $\begin{array}{l}\text { Postschool education vs no postschool } \\
\text { education (index) }\end{array}$ & -0.52 & 0.25 & -1.00 to $-0.03^{*}$ & -0.33 & 0.37 & -1.07 to 0.40 & -0.99 & 0.56 & -2.08 to 0.11 \\
\hline Married vs not married (index) & -0.07 & 0.19 & -0.44 to 0.31 & -0.15 & 0.23 & -0.61 to 0.31 & -0.10 & 0.39 & -0.87 to 0.67 \\
\hline Age & -0.002 & 0.01 & -0.02 to 0.01 & 0.02 & 0.009 & 0.01 to $0.04^{*}$ & 0.02 & 0.02 & -0.01 to 0.05 \\
\hline Change in unpaid work hours per day & -0.14 & 0.03 & -0.19 to $-0.09^{*}$ & -0.21 & 0.04 & -0.27 to $-0.14^{*}$ & -0.38 & 0.05 & -0.49 to $-0.28^{*}$ \\
\hline \multicolumn{10}{|l|}{ Step 3: interaction } \\
\hline $\begin{array}{l}\text { Change in visual acuity } \times \text { change in paid } \\
\text { work (interaction) }\end{array}$ & 0.01 & 0.03 & -0.05 to 0.07 & 0.05 & 0.03 & 0.00 to 0.11 & 0.05 & 0.05 & -0.05 to 0.15 \\
\hline \multicolumn{10}{|c|}{$\begin{array}{l}{ }^{*} \mathrm{p}<0.05 . \\
+N e g a t i v e \text { coefficients indicate an increase in the respective variable alongside a decrease in the respective SRQ-20 score. } \\
\text { †Lower values for visual acuity correspond to better visual acuity. } \\
\text { SRQ-20, Self-Reporting Questionnaire-20. }\end{array}$} \\
\hline
\end{tabular}


Further studies might investigate a broader range of covariates when exploring reductions in psychological distress. Candidates might include sleep patterns, extent of family support or overall physical health. It will be important for the temporal sequence of these changes to be documented to foster an understanding of which domains might need to improve to facilitate changes in other areas. Nonetheless, the present findings indicate that there are persisting psychological benefits of cataract surgery in developing countries and that these benefits may arise in tandem with improved engagement in occupational and domestic activities.

This study provides further evidence indicating heightened rates of psychological distress among people with cataract within an LMIC setting and the potential for such distress to be lowered through surgery. The findings extend previous research by demonstrating that psychological distress is not limited to those presenting to tertiary hospital services, the focus of previous research in Vietnam, but is also evident among patients identified during a community outreach programme across urban and rural settings. The provision of cataract surgery by outreach thus has significant potential public health benefits, although we note that in the present sample, hospital participants showed relatively greater reductions in psychological distress. This finding points towards the importance of ensuring that outreach programmes are able to replicate key features of hospital care through regular follow-up access to medications, or alternatively ensuring that access to hospital care is extended more broadly.

The findings underscore the multiple health burdens associated with untreated cataracts in LMIC settings. The prospective nature of the research following cataract surgery documented a substantial reduction in psychological distress at 12 months follow-up with most patients moving from clinical to non-clinical ranges of psychological distress. There were also clear moderator effects with the greatest reductions in psychological distress associated with the greatest gains in the number of hours of paid and unpaid work, highlighting the diverse benefits that may follow successful cataract surgery.

\section{Handling editor Soumitra Bhuyan}

Twitter Follow Lisa Keay @KeayLisa

Acknowledgements The named authors wish to acknowledge the contribution of the broader VISIONARY Study team which contributed to the development and piloting of the study tools and assisted with data collection. VISIONARY was a collaborative academic study coordinated jointly by investigators at The George Institute for Global Health and The Fred Hollows Foundation in Australia and Vietnam.

Contributors DB conducted the data analysis and interpretation and drafted the manuscript. ZS and LK oversaw the data analysis and interpretation and contributed to the drafting of the manuscript. BME, SJ and MLH conceived of and designed the study, including drafting of the protocol, developed all research tools, trained the research staff and contributed to the drafting of the manuscript. HTP assisted in the design of the study and its implementation in Vietnam and provided comments on the manuscript. All authors read, edited and approved the final manuscript.
Funding The study was funded by a grant provided by The Fred Hollows Foundation, Australia. The research team had full control of all primary data. During the course of this work, BME was in receipt of an lan Potter Foundation Fellowship and a National Health and Medical Research Council (NHMRC) fellowship (1072148), SJ received an NHMRC Senior Research Fellowship, and MLH was in receipt of a National Heart Foundation Future Leader Fellowship 100034.

\section{Competing interests None declared.}

Ethics approval The study was approved by The University of Sydney Human Research Ethics Committee (protocol number: 13407).

Provenance and peer review Not commissioned; externally peer reviewed.

Data sharing statement No additional data are available.

Open Access This is an Open Access article distributed in accordance with the Creative Commons Attribution Non Commercial (CC BY-NC 4.0) license, which permits others to distribute, remix, adapt, build upon this work noncommercially, and license their derivative works on different terms, provided the original work is properly cited and the use is non-commercial. See: http:// creativecommons.org/licenses/by-nc/4.0/

\section{REFERENCES}

1. World Health Organization. Global data on visual impairments 2010. Geneva: World Health Organization, 2012.

2. Owsley C, Stalvey B, Wells J, et al. Older drivers and cataract: driving habits and crash risk. J Gerontology A Biol Sci Med Sci 1999;54:M203-11.

3. Hodge W, Horsley T, Albiani D, et al. The consequences of waiting for cataract surgery: a systematic review. CMAJ 2007; 176:1285-90.

4. Freeman EE, Gresset J, Djafari F, et al. Cataract-related vision loss and depression in a cohort of patients awaiting cataract surgery. Can J Ophthalmol 2009;44:171-6.

5. El-Gabalawy R, Mackenzie CS, Shooshtari S, et al. Comorbid physical health conditions and anxiety disorders: a population-based exploration of prevalence and health outcomes among older adults. Gen Hosp Psychiatry 2011;33:556-64.

6. Hayman KJ, Kerse NM, La Grow SJ, et al. Depression in older people: visual impairment and subjective ratings of health. Optom Vis Sci 2007;84:1024-30.

7. Agarwal A, Kumar DA. Cost-effectiveness of cataract surgery. Curr Opin Ophthalmol 2011;22:15-18.

8. McGwin GJr, Li J, McNeal S, et al. The impact of cataract surgery on depression among older adults. Ophthal Epidemiol 2003;10:303-13.

9. Harwood RH, Foss AJ, Osborn F, et al. Falls and health status in elderly women following first eye cataract surgery: a randomised controlled trial. Br J Ophthalmol 2005;89:53-9.

10. Gray CS, Karimova G, Hildreth AJ, et al. Recovery of visua and functional disability following cataract surgery in older people: Sunderland cataract study. J Cataract Refract Surg 2006;32:60-6.

11. Fraser ML, Meuleners LB, Lee AH, et al. Vision, quality of life and depressive symptoms after first eye cataract surgery. Psychogeriatr 2013:13:237-43.

12. Meuleners LB, Hendrie D, Fraser ML, et al. The impact of first eye cataract surgery on mental health contacts for depression and/or anxiety: a population-based study using linked data. Acta Ophthalmol Scand 2013;91:e445-9.

13. Resnikoff S, Pascolini D, Etya'ale D, et al. Global data on visual impairment in the year 2002. Bull World Health Organ 2004;82:844-51.

14. Brian G, Taylor H. Cataract blindness-challenges for the 21st century. Bull World Health Organ 2001;79:249-56.

15. To KG, Meuleners LB, Fraser ML, et al. The impact of cataract surgery on depressive symptoms for bilateral cataract patients in Ho Chi Minh City, Vietnam. Int Psychogeriatr 2014;26: 307-13.

16. Polack S, Eusebio C, Mathenge W, et al. The impact of cataract surgery on health related quality of life in Kenya, the Philippines, and Bangladesh. Ophthal Epidemiol 2010;17:387-99.

17. Lagerveld SE, Blonk RW, Brenninkmeijer V, et al. Work-focused treatment of common mental disorders and return to work: a comparative outcome study. J Occup Health Psychol 2012;17:220-34. 
18. Huang $Y$, Bocchi AM. Lessons from experience: reshaping economic geography in East Asia. Washington DC: The World Bank, 2009.

19. Shen $Y C$, Zhang MY, Huang $Y Q$, et al. Twelve-month prevalence, severity, and unmet need for treatment of mental disorders in metropolitan China. Psychol Med 2006;36:257-67.

20. Steel Z, Silove D, Giao NM, et al. International and indigenous diagnoses of mental disorder among Vietnamese living in Vietnam and Australia. Br J Psychiatry 2009;194:326-33.

21. Watson D, Clark LA, Carey G. Positive and negative affectivity and their relation to anxiety and depressive disorders. J Abnorm Psychol 1988;97:346-53.

22. Stratton KJ, Aggen SH, Richardson LK, et al. Evaluation of the psychometric properties of the self-reporting questionnaire (SRQ-20) in a sample of Vietnamese adults. Compr Psychiatry 2013;54:398-405.

23. Essue BM, Hackett ML, Mueller A, et al. inVestlgating the pSychologlcal and ecONomic impAct of cataRact surgerY in Vietnam: the VISIONARY observational study protocol. BMC Ophthalmol 2011;11:25.

24. General Statistical Office of Viet Nam. Statistical Data [Internet]. General Statistical Office of Viet Nam. 2016. https://www.gso.gov.vn/ Default en.aspx?tabid=766 (accessed 5 Jul 2016).

25. Ministry of Culture and Information. Industry Sector: Thai Binh [Internet]. General Statistical Office of Viet Nam; 2013. http://english. thaibinh.gov.vn/Tin-Tuc/Socialconditions/278_Industry-sector (accessed 28 Dec 2016).

26. Lensink R, Van Nam M. Economic development of the Mekong delta in Vietnam. Groningen, NL, CDS, 2008. http://www.rug.nl/research/ portal/publications/economic-development-of-the-mekong-delta-invietnam(cb3bd4d7-c182-4c5c-8ab7-a97511d89e3e).html

27. Giang KB, Allebeck P, Kullgren G, et al. The Vietnamese version of the self reporting questionnaire 20 (SRQ-20) in detecting mental disorders in rural Vietnam: a validation study. Int J Soc Psychiatry 2006;52:175-84.

28. Beusenberg M, Orley J. A user's guide to the Self Reporting Questionnaire (SRQ). Geneva: World Health Organisation, 1994.
29. Harding TW, de Arango MV, Baltazar J, et al. Mental disorders in primary health care: a study of their frequency and diagnosis in four developing countries. Psychol Med 1980;10:231-41.

30. Mari JJ, Williams P. A comparison of the validity of two psychiatric screening questionnaires (GHQ-12 and SRQ-20) in Brazil, using Relative Operating Characteristic (ROC) analysis. Psychol Med 1985;15:651-9.

31. Mari JJ, Williams P. Misclassification by psychiatric screening questionnaires. J Chronic Dis 1986;39:371-8.

32. Araya R, Wynn R, Lewis $\mathrm{G}$. Comparison of two self administered psychiatric questionnaires (GHQ-12 and SRQ-20) in primary care in Chile. Soc Psychiatry Psychiatr Epidemiol 1992;27:168-73.

33. Richardson LK, Amstadter AB, Kilpatrick DG, et al. Estimating mental distress in Vietnam: the use of the SRQ-20. Int J Soc Psychiatry 2010;56:133-42.

34. Tuan T, Harpham T, Huong NT. Validity and reliability of the Self-Reporting Questionnaire 20 items in Vietnam. Hong Kong J Psychiatry 2004;14:15-8.

35. General Statistical Office of Viet Nam. Vietnamese Household Living Standards Survey, 5th round [Internet]. General Statistical Office of Viet Nam. 2010. http://www.gso.gov.vn/default.aspx? tabid=512\&idmid=5\&ltemID=8182 (accessed $11 \mathrm{Jul} 2016$ ).

36. Fitzmaurice GM, Laird NM, Ware JH. Applied longitudinal analysis. 2nd edn. Hoboken, NJ: Wiley, 2011.

37. Gilbert CE, Shah SP, Jadoon MZ, et al. Poverty and blindness in Pakistan: results from the Pakistan national blindness and visual impairment survey. BMJ 2008;336:29-32.

38. Dandona L, Dandona R, Srinivas M, et al. Blindness in the Indian state of Andhra Pradesh. Investig Ophthalmol Vision Sci 2001;42:908-16.

39. Essue BM, Li Q, Hackett ML, et al. A multicenter prospective cohort study of quality of life and economic outcomes after cataract surgery in Vietnam: the VISIONARY study. Ophthalmology 2014;121:2138-46.

40. Steel Z, Chey T, Silove D, et al. Association of torture and other potentially traumatic events with mental health outcomes among populations exposed to mass conflict and displacement: a systematic review and meta-analysis. JAMA 2009;302:537-49. 